American Journal of Pharmaceutical Education 2021; 85 (5) Article 8283.

\title{
COMMENTARY
}

\section{Strategies to Bring Transgender and Non-binary Health Care into Pharmacy Education}

\author{
Cheyenne C. Newsome, PharmD ${ }^{\mathrm{a}}$, Alexander Gilmer, PharmD ${ }^{\mathrm{b}}$ \\ ${ }^{a}$ Washington State University, College of Pharmacy and Pharmaceutical Sciences, Spokane, Washington \\ ${ }^{\mathrm{b}}$ University of California, San Francisco Medical Center, San Francisco, California
}

Submitted July 8, 2020; accepted December 30, 2020; published May 2021.

\begin{abstract}
Research has shown an increase in the number of people in the United States identifying as transgender and non-binary (TNB) . Many pharmacy schools and colleges do not offer any instruction specific to students interacting with and caring for TNB people, and practicing pharmacists have reported a lack of confidence in managing TNB patients. Regardless of the practice setting they choose, there is an increased likelihood that pharmacy graduates will serve TNB patients. Pharmacy schools that include TNB-specific education in their Doctor of Pharmacy curriculum will equip graduates with the necessary knowledge and skills to support this vulnerable population. The purpose of this commentary is to suggest methods for incorporating TNB-related material into pharmacy curricula and to provide resources for developing content.
\end{abstract}

Keywords: pharmacy education, LGBTQ, transgender, health care education, transgender-related care

\section{INTRODUCTION}

A transgender or non-binary (TNB) person has a gender identity different than their sex assigned at birth. As awareness and acceptance of TNB people grows, the number of TNB people seeking gender affirming therapy is also increasing. ${ }^{1}$ Gender-affirming therapy is individualized care that may include medical or surgical interventions to change a person's outward gender expression to match their gender identity. An estimated 1.4 million adults in the United States ( $0.6 \%$ of the population) are TNB. ${ }^{2}$ About $0.7 \%$ of US high school students are thought to be TNB, and estimates of the TNB youth population are as high as $3 \%-12 \%{ }^{3,4}$ With increasing numbers of TNB people living their authentic lives, there is a high likelihood that student pharmacists will serve this population during school and throughout their careers.

While the American Association of Colleges of Pharmacy (AACP) advocates for diversity education that includes gender, most student pharmacists graduate inadequately prepared to provide optimal health care for TNB patients. ${ }^{5,6}$ A 2016 publication from Leach and Layson-Wolf examined community pharmacy residents' perceptions of TNB health management. The study found that while $83 \%$ of the residents believed that community

Corresponding Author: Cheyenne C. Newsome, Washington State University, College of Pharmacy and Pharmaceutical Sciences, 412 E. Spokane Falls Blvd., Spokane, WA 99210. Tel: 509-358-7913. Email: cheyenne.newsome@wsu.edu pharmacists have an important role in TNB health care, only $36 \%$ of them felt confident enough to take on that role. Additionally, $72 \%$ reported receiving no education regarding TNB care while in pharmacy school. ${ }^{7}$ A 2018 survey of community pharmacists in North Carolina found that only $36 \%$ felt comfortable asking patients what pronoun they use, which is, one of the most important aspects to appropriately address TNB patients. ${ }^{8}$ Tran and colleagues had similar findings in a 2019 survey related to pharmacists' knowledge of gender affirming therapy. The majority of respondents believed that providing gender affirming therapy and being comfortable interacting with TNB patients were highly important. However, nearly $40 \%$ of the respondents rated themselves as "not at all prepared" to counsel TNB patients on gender affirming therapy regimens. ${ }^{9}$ Furthermore, a survey of 316 US TNB people found that although $90 \%$ of them used pharmacists' services, almost half reported having apprehension about experiencing discrimination at the pharmacy. Fiftyfour percent of the respondents perceived pharmacists as having little to no knowledge of TNB-related health care. ${ }^{10}$ The lack of confidence reported by pharmacists and knowledge gaps observed by TNB patients are likely due to a lack of education in pharmacy programs and severely limited continuing education opportunities in this area for practicing pharmacists. Another factor might lie with the pharmacists themselves and a lack of interest in seeking TNB-related education; however, interest may grow as more pharmacists interact with TNB people. 


\section{American Journal of Pharmaceutical Education 2021; 85 (5) Article 8283.}

Eckstein and colleagues evaluated the incorporation of TNB-related care in pharmacy school curricula. Among the 66 pharmacy programs that responded to a 2018 survey, 53\% addressed TNB care within their curriculum while $13 \%$ did not address the topic at all and had no plans to do so in the next three years. ${ }^{6}$ This commentary discusses the value of inclusion of TNB-centered material in pharmacy education, explores approaches for integration of TNB patient care into curricula, and provides resources for developing content.

\section{DISCUSSION}

\section{Health Disparities Among Transgender and Non- binary Persons}

The term transgender is frequently used as an umbrella term describing someone whose gender identity differs from the sex they were assigned at birth. The term cisgender, or non-TNB, describes someone whose gender identity is the same as their sex assigned at birth. Typically, sex is assigned at birth based on genitals. Gender identity, however, is the brain's understanding of "self" as a woman, a man, a combination of both, or neither, and is usually established at around two to six years of age. ${ }^{12}$ Non-binary persons identify as being other than a man or woman or not exclusively a man or woman. Gender nonconforming people have gender expressions and/or identities outside of societal norms. Not all non-binary people identify as transgender. Thus, we have chosen the term TNB to ensure inclusion of a broader range of people with transgender and non-binary identities. Because many non-binary people also identify as transgender, we chose to use TNB rather than the term transgender when discussing published studies that did not specifically delineate between transgender and non-binary identities.

The TNB community experiences significant disparities across all determinants of health, including higher rates of homelessness, unemployment, and poverty. ${ }^{12-14}$ Additionally, experiences of violence and victimization are frequent for TNB individuals and result in long-lasting effects on both the individual and the community. ${ }^{12,15,16}$ According to the National Transgender Discrimination Survey, $40 \%$ of TNB people reported suicide attempts, as compared with $4.6 \%$ of the general population. ${ }^{13}$ There is strong evidence that gender affirming care, including pharmacotherapy, is highly effective at resolving gender dysphoria while also improving the patient's quality of life. However, TNB patients often face barriers when seeking medical care. ${ }^{17}$ One in four adult TNB patients will delay necessary health care for fear of discrimination. ${ }^{12}$ Transgender and non-binary youth have also reported avoiding doctor check-ups more frequently than their non-TNB counterparts. ${ }^{18}$ In addition to dealing with discrimination and bias, more than half of TNB patients describe feeling obligated to educate their provider in order to receive appropriate care. ${ }^{12}$ For instance, a recent US survey reported that $71 \%$ of TNB patients found it necessary to enlighten providers at some point. Roughly $20 \%$ of respondents obtained prescription medications from close contacts or online pharmacies that do not require a prescription. Moreover, $46 \%$ chose to use natural products to avoid needing a prescription altogether. ${ }^{10}$

\section{Current Status of TNB Care in Health Care Profe- ssional Education}

Health care professional education programs, including medicine, nursing, and physical therapy, have identified curriculum gaps in patient care education regarding lesbian, gay, bisexual, TNB, and queer $\left(\right.$ LGBTQ +) persons. ${ }^{6,19-21}$ Nearly a decade ago, Parkhill and colleagues described the need for TNB health content in pharmacy curricula. ${ }^{21}$ The Association of American Medical Colleges (AAMC) released a report in 2007 recommending incorporation of educational activities addressing the needs of LGBTQ+ students and patients. $^{22}$ In 2014, the AAMC released another report detailing curricular and institutional climate change recommendations necessary to improve health care for LGBTQ + individuals. ${ }^{23}$ This report encouraged schools to teach excellent communication skills and comprehensive care for the LGBTQ+ population. The report included 30 competencies that could be integrated into schools' curricula. Medical schools that added more hours of LGBTQ + topics into existing classes ascertained that students were more prepared and comfortable caring for the LGBTQ+ patient population. ${ }^{24,25}$ In 2018, the American Nursing Association released a position statement titled, "Nursing Advocacy for LGBTQ+ Populations" which "affirms the need for nurses in all roles and settings to provide culturally congruent, competent, sensitive, safe, inclusive, and ethical care to members of LGBTQ + populations, as well as to be informed and educated about the provision of culturally competent care." ${ }^{26}$ However, while the gaps in LGBTQ+ curricula have been identified and schools have begun integrating this curricula into their programs, inadequate acknowledgement or inclusion of TNB-specific health care needs and education still remains throughout all health professions. $^{6-9,27}$

\section{Overcoming Barriers to Including TNB Health Care in Pharmacy Curricula}

Reasons for the lack of TNB-related instruction in pharmacy curricula may be multifactorial. Eckstein and colleagues reported that $47 \%$ of pharmacy programs had 


\section{American Journal of Pharmaceutical Education 2021; 85 (5) Article 8283.}

no access to qualified faculty able to teach TNB-related care in their curricula. ${ }^{6}$ While faculty may not have received specific training or have extensive experience caring for TNB people, it is possible for them to educate themselves in this area so that they are able to teach students. It is not uncommon for faculty, especially junior faculty, to lecture on topics in which they possess limited first-hand clinical experience. Free resources available to faculty for self-education on appropriate terminology and practice guidelines related to serving TNB patients are listed in Table 1. Furthermore, faculty can have outside experts and consultants present on the topic or faculty can collaborate with an expert to develop content. Ideally, pharmacy education in TNB patient care should be accurate and comprehensive. For example, if non-binary patients are left out of the discussion, students may not be able to provide quality care for these individuals.
Other barriers cited by pharmacy programs to incorporating content on TNB patient care in the curriculum include difficulty in changing the curriculum (33\%) and not having enough time to teach TNB patient care within the curriculum $(21 \%){ }^{6}$ While a complete overhaul to the Doctor of Pharmacy curricula in general remains a longterm goal, it is possible to immediately integrate material regarding TNB patients within existing courses. For example, instructional patient cases can introduce TNB patients for any disease state to facilitate student exposure and familiarity. This could include commonly described disease states such as hypertension, diabetes, or pneumonia. Specifically, it is vital that educators avoid relevant communication about TNB being limited to discussions surrounding sexually transmitted infections or hormonal pharmacotherapy. There are several journals articles that describe ways in which pharmacy schools

Table 1. References to Develop Curricular Material for Transgender and Non-binary Care in the Doctor of Pharmacy Curriculum

\begin{tabular}{|c|c|c|}
\hline Reference & Date of Last Update & Topics Included \\
\hline $\begin{array}{l}\text { University of California- San Francisco } \\
\text { Center of Excellence for Transgender } \\
\text { Health https://transcare.ucsf.edu/ } \\
\text { guidelines }\end{array}$ & Web-based continuously updated & $\begin{array}{l}\text { Terminology, creating safe and } \\
\text { welcoming environment, hormone } \\
\text { treatment, overviews of masculinizing } \\
\text { and feminizing therapies, dosing, }\end{array}$ \\
\hline $\begin{array}{l}\text { Endocrine Treatment of Gender- } \\
\text { Dysphoric/Gender-Incongruent } \\
\text { Persons: An Endocrine Society Clinical } \\
\text { Practice Guideline https:// } \\
\text { www.endocrine.org/clinical-practice- } \\
\text { guidelines/gender-dysphoria-gender- } \\
\text { incongruence }\end{array}$ & Sept 2017 & $\begin{array}{l}\text { monitoring, comorbid conditions } \\
\text { Terminology, diagnosis and assessment, } \\
\text { medication dosing, monitoring, effects } \\
\text { with timeline, }\end{array}$ \\
\hline $\begin{array}{l}\text { Williams Institute Report "How Many } \\
\text { Adults Identify as transgender in the } \\
\text { United States?"'https:// } \\
\text { williamsinstitute.law.ucla.edu/ } \\
\text { publications/trans-adults-united-states/ }\end{array}$ & June 2016 & $\begin{array}{l}\text { Estimated prevalence of patients who are } \\
\text { transgender in US }\end{array}$ \\
\hline $\begin{array}{l}\text { The National Center for Transgender } \\
\text { Equality The Report of the } 2015 \text { U.S. } \\
\text { Transgender Survey https:// } \\
\text { transequality.org/issues/us-trans-survey }\end{array}$ & 2016 & Terminology, health disparities \\
\hline $\begin{array}{l}\text { World Professional Association of } \\
\text { Transgender Health (WPATH) } \\
\text { Standards of Care https:// } \\
\text { www.wpath.org/publications/soc }\end{array}$ & $\begin{array}{l}\text { 2012, (some sections are outdated, update } \\
\text { in progress, new guidelines expected } \\
\text { 2021) }\end{array}$ & $\begin{array}{l}\text { Terminology, review of medications and } \\
\text { formulations (no dosing), effects of } \\
\text { hormones with timeline, adverse effects } \\
\text { of hormone therapy }\end{array}$ \\
\hline $\begin{array}{l}\text { Minus18 } \\
\text { What Are Pronouns? } \\
\text { Trans 101: The Basics } \\
\text { Trans 101: Being an Ally https:// } \\
\text { www.minus18.org/au } \\
\text { https://www.youtube.com/user/ } \\
\text { Minus18TV/videos }\end{array}$ & Web-based continuously updated & $\begin{array}{l}\text { Terminology, pronouns, cultural } \\
\text { awareness/humility, allyship }\end{array}$ \\
\hline
\end{tabular}




\section{American Journal of Pharmaceutical Education 2021; 85 (5) Article 8283.}

have incorporated transgender pharmacy care into their curriculum that can serve as useful resources. ${ }^{28-31}$

Additional obstacles to further development or implementation of TNB content in pharmacy curricula are an absence of interest in including these topics (15\%) and lack of support from the faculty $(8 \%) .^{6}$ It is important to acknowledge that faculty are not required to fully understand or morally agree with a TNB patient's choices in order to be supportive and provide them with evidencebased medicine and life-saving affirming care. Faculty can empower students to be empathetic and provide quality care regardless of their personal beliefs.

The inclusion of TNB health care meets several of the Accreditation Council for Pharmacy Education (ACPE) Standards 2016..$^{5}$ In case-based learning, educators can create cases with a TNB patient and require the student to evaluate the patient as a whole to make specific recommendations for gender affirming care or other conditions to meet Standard 2.1 (Patient-centered Care). Standard 2.4 (Population based care) and Standard 3.5 (Cultural sensitivity) can be met by discussing health disparities among TNB patients and guiding students regarding the value of using non-gendered language or pronouns.

Appropriately inquiring about and being supportive of a patient's gender identity enhances the patient-provider interaction and encourages regular use of care. ${ }^{32}$ Students should reflect on their beliefs and attitude about TNB people for their awareness and personal growth and to be able to meet Standard 4.1 (Self-Awareness). Having students examine their own gender identity offers powerful opportunities to gain self-awareness of implicit biases and learn how these often subconscious preconceptions impact patient care. Two examples of thoughtprovoking questions are "How did you know what your gender was?" and "What reactions arise in you when you

Table 2. Topics to Consider for Inclusion of Transgender and Non-binary Care Content in Pharmacy Curricula

\begin{tabular}{|c|c|c|c|}
\hline Topic & Breakdown of Topic & $\begin{array}{c}\text { ACPE } \\
\text { Standard }\end{array}$ & $\begin{array}{c}\text { Potential Placement in } \\
\text { Curriculum }\end{array}$ \\
\hline \multicolumn{4}{|l|}{ Topics Specific to TNB Patients } \\
\hline Transition processes & $\begin{array}{l}\text { name vs. name, pronouns } \\
\text { Discuss legal, social, and physical } \\
\text { transition }\end{array}$ & 3.5 & $\begin{array}{l}\text { Men/Women's Health } \\
\text { Cultural } \\
\text { Competency Pharmacy } \\
\text { Law }\end{array}$ \\
\hline Health disparities & $\begin{array}{l}\text { Share statistics and patient experiences with } \\
\text { healthcare system }\end{array}$ & $2.1,2.4,3.5$ & Cultural Competency \\
\hline Hormone therapy & $\begin{array}{l}\text { Medications: dosing, dosage forms, } \\
\text { administration, expected timelines, } \\
\text { adverse effects/caution, drug-drug } \\
\text { interactions, laboratory monitoring, } \\
\text { counseling }\end{array}$ & $2.1,2.4$ & $\begin{array}{l}\text { Endocrinology } \\
\text { Pharmacotherapy } \\
\text { Men/Women's Health }\end{array}$ \\
\hline $\begin{array}{l}\text { Student exposure and } \\
\text { comfortability }\end{array}$ & $\begin{array}{l}\text { Role play situations, observed structured } \\
\text { clinical exams (OSCEsExperiential } \\
\text { learning with TNB communityPanel } \\
\text { discussions }\end{array}$ & $3.5,4.1$ & Communications \\
\hline \multicolumn{4}{|c|}{ Topics Not Specific to TNB Patients } \\
\hline Unconscious bias & $\begin{array}{l}\text { Reflect on personal views and identify } \\
\text { biases }\end{array}$ & 3.5 & Cultural Competency \\
\hline Intersectionality & $\begin{array}{l}\text { Discuss how race, socioeconomic class, and } \\
\text { gender affect individuals or groups }\end{array}$ & 3.5 & Cultural Competency \\
\hline Social determinants of health & $\begin{array}{l}\text { Discuss how social and economic } \\
\text { conditions impact patients' ability to } \\
\text { engage with the healthcare system }\end{array}$ & 3.5 & Cultural Competency \\
\hline
\end{tabular}




\section{American Journal of Pharmaceutical Education 2021; 85 (5) Article 8283.}

meet a person who tells you they are transgender or nonbinary?" Table 2 lists recommended TNB patient care topics to include in pharmacy curricula.

\section{Treating the Whole TNB Patient}

As noted earlier, several health care professions have identified ways to increase awareness of the LGBTQ+ population. However, TNB patients have medical needs that reach beyond cultural competency. Discussion of increased prevalence of HIV, depression, suicide, and substance abuse is often found in the medical and pharmacy literature regarding the TNB community and the majority of research focuses on these areas. Nonetheless, the association between marginalized gender identities and other physical health outcomes is lesser known. In a study comparing TNB and cisgender Medicare beneficiaries, TNB people were younger but had more chronic conditions than their non-transgender counterparts. These conditions included higher rates of asthma, neurological/ chronic pain conditions, obesity, chronic obstructive pulmonary disease (COPD), and hepatitis and other liver conditions. ${ }^{33}$ Additionally, a 2014 study found that TNB individuals were at higher risk for having poor general health, more days per month with poor physical health, and myocardial infarction, regardless of hormone use. Transgender and non-binary individuals were also less likely to utilize primary or dental care services or have access to health insurance. However, contrary to the findings of other studies, TNB individuals were no more likely to smoke or binge drink than non-TNB individuals. ${ }^{34}$

Ideally, TNB patient care should be woven throughout the curriculum so students have multiple exposures to reinforce and expand on previously learned materials. While there are components of TNB patient care that are specific to the TNB population, TNB patients are susceptible to the same disease states as cisgender patients. By focusing solely on conditions related to gender identity, students may not view TNB patients holistically or recognize health care needs outside of their gender identity.

\section{CONCLUSION}

In several published studies, US pharmacists' have reported having a lack of self-confidence in communicating with and caring for TNB patients. This combined with TNB patients' mistrust of pharmacists' ability to adequately and respectfully care for them demonstrate a need for improved and increased education in this area in order for pharmacy schools to graduate pharmacists who are competent in providing health care to TNB individuals. As an Academy, we have an opportunity to develop pharmacy graduates equipped with the knowledge and skills to improve health care for one of the United States' most at-risk populations. While pharmacy programs have begun to include some content on TNB health care, an increase in the inclusion of TNB-related care would equip graduates to improve the care for all patients, regardless of their gender identity.

\section{REFERENCES}

1. Nolan IT, Kuhner CJ, Dy GW. Demographic and temporal trends in transgender identities and gender confirming surgery. Trans Androl Urol. 2019.;8(3):184-190.

2. Flores AR, Herman JL, Gates GJ, Brown TNT. How Many Adults Identify as Transgender in the United States? The Williams Institute. 2016. https://williamsinstitute.law.ucla.edu/wp-content/uploads/ Trans-Adults-US-Aug-2016.pdfAccessed April 30, 2021.

3. Herman JL, Flores AR, Brown TNT, Wilson BDM, Conron KJ. Age of Individuals who Identify as Transgender in the United States. The William's Institute. 2017. https://williamsinstitute.law.ucla.edu/ wp-content/uploads/Age-Trans-Individuals-Jan-2017.pdfAccessed April 30, 2021.

4. Gay and Lesbian Association Against Defamation. Accelerating Acceptance 2017. March 2017. https://www.glaad.org/files/aa/ 2017_GLAAD_Accelerating_Acceptance.pdf. Accessed April 30, 2021. 5. Accreditation Council for Pharmacy Education. Accreditation standards and key elements for the professional program in pharmacy leading to the doctor of pharmacy degree ("Standards 2016") https:// www.acpe-accredit.org/pdf/Standards2016FINAL.pdf. Published February 2, 2015. Accessed April 30, 2021.

6. Eckstein MA, Newsome CC, Borrego ME, Burnett A, Wittstrom $\mathrm{K}$, Conklin JR. A cross-sectional survey evaluating transgenderrelated care education in United States pharmacy school curricula. Curr Pharm Teach Learn. 2019;11(8):782-792.

7. Leach C, Layson-Wolf C. Survey of community pharmacy residents' perceptions of transgender health management. $J \mathrm{Am}$ Pharm Assoc. 2016;56(4):441-445.

8. Aragon KG, Conklin J, Lenell A, Rhodes LA, Marciniak MW. Examining community-based pharmacist perceptions on the care of transgender patients. J Am Pharm Assoc. 2019;59(4S):S62-S66. 9. Tran MT, Swank SD, Oliver AS, Lipscomb JS. Pharmacists perceptions and preparedness regarding gender-affirming hormone therapy. J Am Pharm Assoc. 2021;61(1):e30-e34.

10. Lewis NJW, Batra P, Misiolek BA, Rockafellow S, Tupper C. Transgender/gender nonconforming adults' worries and coping actions related to discrimination: Relevance to pharmacist care. $A m J$ Health-Syst Pharm. 2019;76:512-520.

11. Rafferty J. Gender Identity Development in Children. healthychildren.org. Updated September 18, 2018. https:// www.healthychildren.org/English/ages-stages/gradeschool/Pages/ Gender-Identity-and-Gender-Confusion-In-Children.aspx. Accessed on April 30, 2021.

12. James SE, Herman JL, Rnakin S, Keisling M, Mottet L, Anafi M. The report of the 2015 US transgender survey. Washington, DC. National Center for Transgender Equality. 2016. https:// www.transequality.org/sites/default/files/docs/usts/USTS\%20Full\% 20Report\%20-\%20FINAL\%201.6.17.pdf. Accessed April 30, 2021. 13. Martinez-Velez JJ, Melin K, Rodriguez-Diaz CE. A preliminary assessment of selected determinants of health in a sample of transgender and gender nonconforming individuals in Puerto Rico. Transgend Health 2019;4(1):9-17. 


\section{American Journal of Pharmaceutical Education 2021; 85 (5) Article 8283.}

14. Pega F, Veale JF. The case for the world health organization's commission on social determinants of health to address gender identity. Am J Public Health. 2015;105(3):e58-e62.

15. Testa RJ, Sciacca LM, Wang F, et al. Effects of violence on transgender people. Prof Psych: Res and Pract. 2012;43(5),452-459. 16. Grant JM, Mottet LA, Tanis J, et al. Injustice at Every Turn: A Report of the National Transgender Discrimination Survey. Washington: National Center for Transgender Equality and National Gay and Lesbian Task Force; 2011. https://ransequality.org/sites/default/files/docs/ resources/NTDS_Report.pdf Accessed April 30, 2021.

17. Murad MH, Elamin MB, Garcia MZ, et al. Hormonal therapy and sex reassignment: a systematic review and meta-analysis of quality of life and psychosocial outcomes. Clin Endocrinol (Oxf). 2010;72:214. 18. Rider GN, McMorris BJ, Gower AL, Coleman E, Eisenberg ME. Heath and care utilization of transgender and gender nonconforming youth: a population-based study. Pediatrics 2018;141(3):e20171683. 19. Carabez R, Pellegrini M, Mankovitz A, Eliason M, Ciano M, Scott M. "Never in All My Years... ": Nurses' Education About LGBT Health. J Prof Nurs. 2015;31(4):323-329.

20. Copti N, Shahriari R, Wanek L, Fitzsimmons A. Lesbian, gay, bisexual, and transgender inclusion in physical therapy: advocating for cultural competency in physical therapist education across the United States. J Physical Therapy Education. 2016;30(4):11-16. 21. Parkhill AL, Gainsburg J, Fearing S, Mathews JL. The need for transgender health content in the pharmacy curriculum. Innov Pharm. 2011;2(4): Article 58.

22. Association of American Medical Colleges. Institutional Programs and Educational Activities to Address the Needs of Gay, Lesbian, Bisexual and Transgender (GLBT) Students and Patients. https:// www.aamc.org/media/28351/download. Accessed April 30, 2021. 23. Association of American Medical Colleges. Implementing Curricular and Institutional Climate Changes to Improve Health Care for Individuals Who are LGBT, Gender Nonconforming, or Born with DSD. https://store.aamc.org/downloadable/download/sample/ sample_id/129/. Accessed April 30, 2021.

24. Brown RD, Clarke B, Gortmaker V, Robinson-Keilig R. Assessing the campus climate for gay, lesbian, bisexual, and transgender (GLBT) students using a multiple perspectives approach. J Coll Stud Dev. 2004;45(1):8-26.

25. Park JA, Safer JD. Clinical exposure to transgender medicine improves students' preparedness above levels seen with Didactic teaching alone: a key addition to the Boston University Model for teaching transgender healthcare. Transgend Health. 2018;3(1):10-16. 26. American Nursing Association. ANA Position Statement: Nursing Advocacy for LGBTQ+ Populations https:// ojin.nursingworld.org/MainMenuCategories/ANAMarketplace/ ANAPeriodicals/OJIN/TableofContents/Vol-24-2019/No1-Jan2019/ANA-Position-Statement-Advocacy-for-LGBTQ.html Accessed April 30, 2021.

27. Dubin SN, Nolan IT, Streed CG Jr, Greene RE, Radix AE, Morrison SD. Transgender health care: improving medical students' and residents' training and awareness. Adv Med Educ Pract. 2018; 9: 377-391.

28. Leach C, Seung H, Layson-Wolf C. Student pharmacists' perceptions of transgender health management. Curr Pharm Teach Learn. 2019;11(12):1254-1258.

29. Newsome C, Chen LW, Conklin J. Addition of care for transgender-related patient care into doctorate of pharmacy curriculum: implementation and preliminary Evaluation. Pharmacy (Basel). 2018;6(4):107.

30. Ostroff JL, Ostroff ML, Billings S, Nemec EC 2nd. Integration of transgender care into a pharmacy therapeutics curriculum. Curr Pharm Teach Learn. 2018;10(4):463-468.

31. Redfern JS, Jann MW. The evolving role of pharmacists in transgender health care. Transgend Health. 2019;4:118-130.

32. Steele LS, Tinmouth JM, Lu A. Regular health care use by lesbians: a path analysis of predictive factors. Fam Pract. 2006;23: 631-636.

33. Meyer IH. Prejudice, social stress, and mental health in lesbian, gay, and bisexual populations: conceptual issues and research evidence. Psychol Bull. 2003;129(5):674-697.

34. Dragon CN, Guerino P, Ewald E, and Laffan AM. Transgender Medicare beneficiaries and chronic conditions: exploring fee-forservice claims data. LGBT Health. 2017;4(6):404-411. 